\title{
DOES MODULAR EXTENSION OF DHS FIX THE UNSTABLE TROCHANTERIC FRACTURES
}

\author{
Sekar Prabhakar1, Raju Prabhakar Singh ${ }^{2}$
}

${ }^{1}$ Senior Assistant Professor, Department of Orthopaedics, Government Kilpauk Medical College and Hospital, Chennai. ${ }^{2}$ Senior Assistant Professor, Department of Orthopaedics, Government Kilpauk Medical College and Hospital, Chennai.

\begin{abstract}
Nowadays, the use of DHS in unstable trochanteric fractures has been associated with significant medial displacement of the shaft resulting from excessive sliding of screw within the barrel and a higher incidence of screw cut out. To emphasise the importance of the modular Trochanter Stabilizing Plate (TSP) in addition to the Dynamic Hip Screw (DHS) prevents excessive telescoping/varus malposition and limb shortening in all unstable trochanteric fractures with lateral wall communitions.
\end{abstract}

\section{MATERIAL AND METHOD}

Twenty five consecutive patients with unstable intertrochanteric fractures were treated with an additional TSP superimposed on the regular DHS at our institution between October 2013 and November 2015. Three patients migrated to other states, one patient was lost to follow-up and another patient refused follow-up. Thus, twenty patients were followed for at least mean of 19 months (Range 6 to 28 months).

\section{RESULTS}

Lateralization of the greater trochanter was successfully prevented in all fractures. Functional results were excellent and good in 87 percent of patients and fair in 13 percent according to the Harris Hip score.

\section{CONCLUSION}

TSP with DHS is a biomechanically stable construct allowing reconstruction of lateral wall to maintain adequate lever arm and abductor strength (Power arm) in unstable intertrochanteric fractures with lateral wall comminution. Two point fixation provides additional rotational stability. Superior functional and radiological outcome favours its use in unstable intertrochanteric fracture.

\section{KEYWORDS}

Intertrochanteric Fractures, Trochanteric Stabilization Plate, Varus Malunion, Buttress Effect, TSP.

HOW TO CITE THIS ARTICLE: Prabhakar S, Singh RP. Does modular extension of DHS fix the unstable trochanteric fractures. J. Evolution Med. Dent. Sci. 2016;5(54):3683-3692, DOI: 10.14260/jemds/2016/846

\section{INTRODUCTION}

Intertrochanteric fractures continues to be a challenge for all orthopaedic surgeons. A variety of implants of internal fixation have been employed to achieve this goal with variable success. The diversity of fixation devices available for the treatment of trochanteric fractures illustrates the difficulties encountered in the actual treatment and the discussion about ideal implant still continues. In recent years, the use of DHS in unstable trochanteric fractures has been associated with significant medial displacement of the shaft resulting from excessive sliding of screw within the barrel and a higher incidence of screw cut-out.(1) Moreover, $12 \%$ of unstable intertrochanteric fractures shows radiologically identifiable rotation of proximal fragment when fixed with DHS, as DHS provides single point fixation over which the proximal fragment rotates on hip movements. This leads to more malunions and nonunions. (2) The stabilization of lateral wall.(3) in unstable fractures by addition of Trochanter Stabilization Plate (TSP) to DHS has been devised to prevent the excessive collapse and varus malpositioning.(4) The purpose of this study was to

Financial or Other, Competing Interest: None.

Submission 27-05-2016, Peer Review 21-06-2016,

Acceptance 27-06-2016, Published 07-07-2016.

Corresponding Author:

Dr. Sekar Prabhakar,

No. 117,

$7^{\text {TH }}$ Cross Street,

Sakthivel Nagar,

Chennai-600082.

E-mail: prabhuortho@gmail.com

DOI: 10.14260/jemds/2016/846 assess the effectiveness of TSP in unstable intertrochanteric fractures with lateral wall comminution with assessment of radiological and functional outcome.

\section{MATERIAL AND METHOD}

This study was conducted in Government Kilpauk Medical College and Hospital, Chennai-10.

\section{Inclusion Criteria}

1. Clinical diagnosis of unstable trochanteric femur fracture (AO Type 31A2.1 to 31A2.3).

2. Age $>40$ years and $<75$ years.

3. Both genders.

\section{Exclusion Criteria}

1. Open fractures.

2. Patients with pathological fractures.

3. Polytrauma patients.

4. Patients not able to walk before the fracture.

5. History of previous surgery on proximal femur fracture.

6. Under 40 years old.

7. Patients with fractures needing other treatments than sliding hip screws.

8. Reverse oblique fractures.

9. Patients with dementia using steroids, immunesuppressant.

Twenty five consecutive patients with unstable intertrochanteric fractures were treated with an additional TSP super-imposed on the regular DHS at our institution 
between October 2013 and November 2015. Three patients migrated to other states, one patient was lost to follow-up and another patient refused follow-up. Thus, twenty patients were followed for mean of 19 months (Range 6 to 28 months).

\section{Investigation Details}

1. Radiological: Plain X-ray of the affected hip with femur in two standard projections (AP and Frog leg lateral view).

2. Complete Haemogram.

3. Renal function test.

4. Bleeding time and Clotting time.

5. Screening for infections - HIV, HBV, Syphilis.

6. Chest X-ray and Electrocardiogram.

7. If needed CT of concerned hip joint with 3D reconstruction.

- Post-operative radiological outcome was assessed by periodic X-rays of affected hip.

- Post-operative functional outcome was assessed by using Harris Hip Score.

\section{Implant}

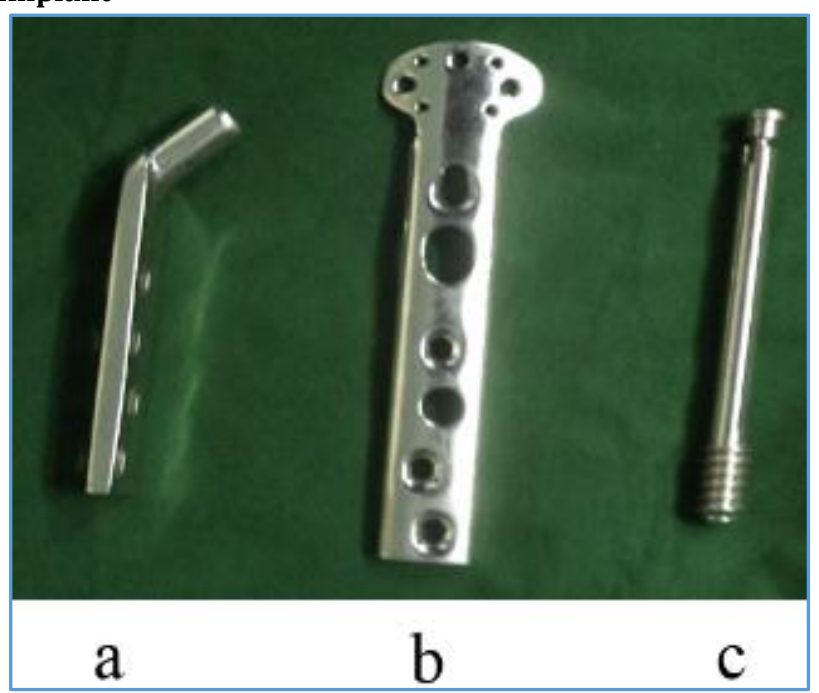

Fig. 1: Trochanteric Stabilisation Plate

a. Standard sliding hip screw barrel plate.

b. Trochanteric Stabilisation Plate.

c. Richard screw.

\section{Operative Method}

Patient prepared on the morning of day of surgery. Preoperatively, prophylactic antibiotic single dose given after test dose on the operation table.

Spinal anaesthesia used for all cases. Patient was placed on fracture table with unaffected leg in flexion and abduction position by using leg holder. Affected leg placed in boot and fixed to the fracture table. $C$ arm placed on the opposite side of affected extremity. Before progressing with fracture reduction $\mathrm{C}$ arm was checked for optimal functioning relative to patient position to ensure proper visualization of fracture in both AP and lateral view by it.

\section{Surgical Technique}

Patient prepared on the morning of day of surgery. Preoperatively, prophylactic antibiotic single dose were given after test dose on the operation table.
Spinal anaesthesia was used for all cases. Patient was placed on fracture table with unaffected leg in flexion and abduction position by using leg holder. Affected leg placed in boot and fixed to the fracture table. $\mathrm{C}$ arm placed on the opposite side of affected extremity. Before progressing with fracture reduction, $\mathrm{C}$ arm was checked for optimal functioning relative to patient position to ensure proper visualization of fracture in both AP and lateral view by it.

\section{Reduction Manoeuvre}

Using preoperative X-rays and perioperative C-arm image fracture pattern studied and closed reduction manoeuvre.(5) planned.

Reduction done using traction and internal or external rotation depending on fracture pattern.

Other deformities like sagittal plane deformity corrected by applying an anteriorly directed force on distal fragment, while simultaneously applying traction.

\section{Surgical Approach}

Operated limb painted and draped in standard fashion for hip surgery in supine position.

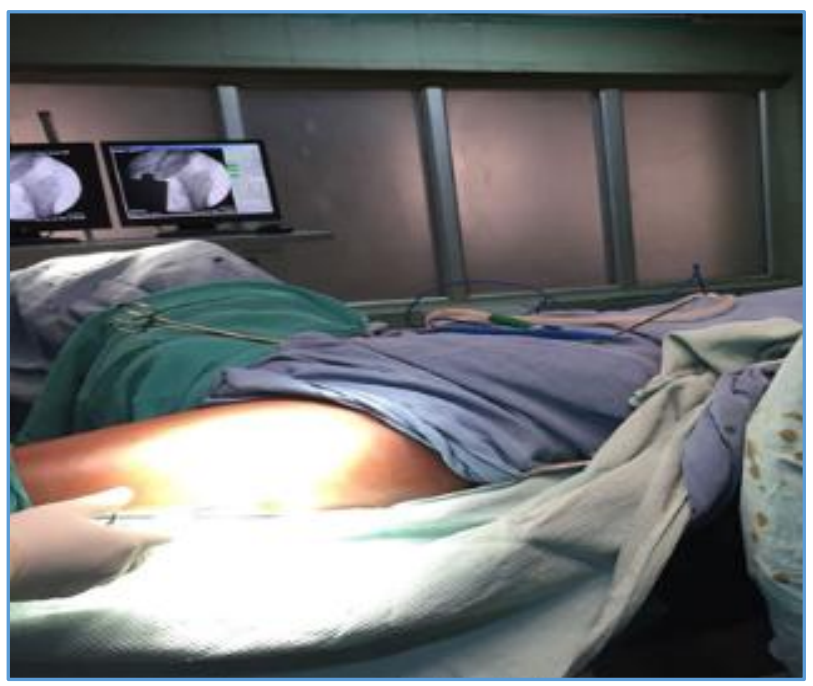

Fig. 2: Patient Position

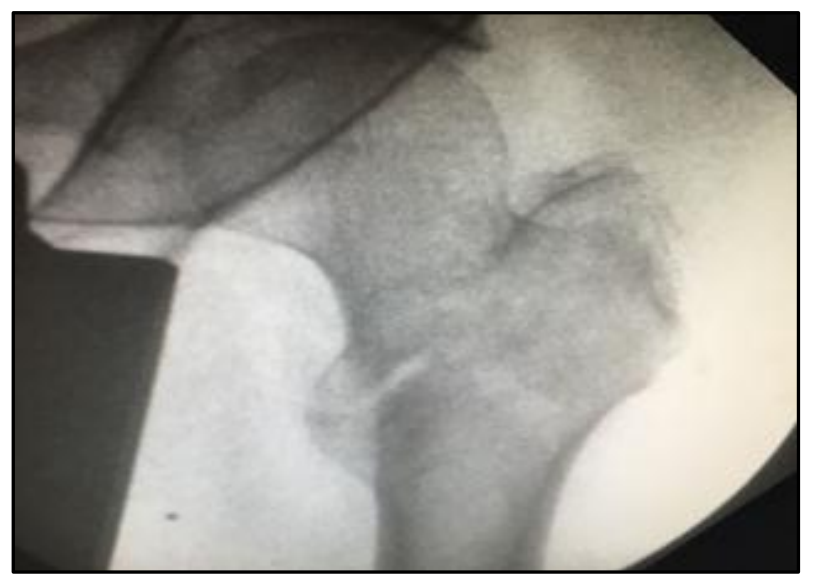

Fig. 3: Intraoperative C-Arm AP View

Standard lateral approach to hip joint utilized for exposing the fracture site. Skin and subcutaneous tissue incised. Tensor fascia lata and Vastus lateralis split and proximal femur exposed. In case inadequate reduction achieved by traction 
and internal rotation as visualized by $\mathrm{C}$-arm open reduction done.

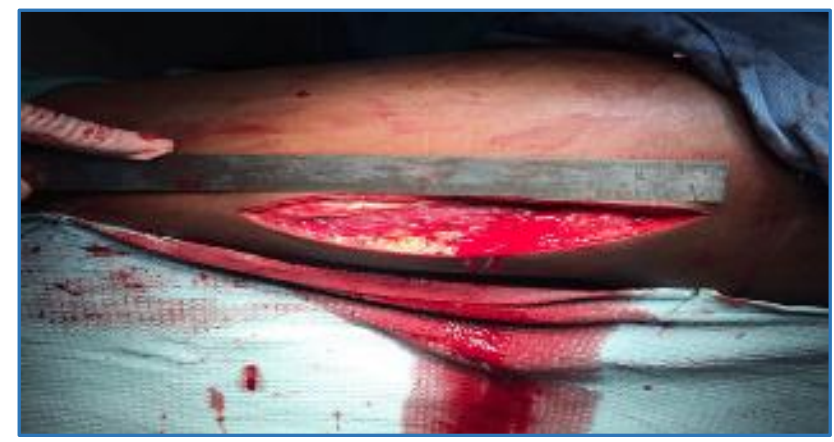

Fig. 4: Skin Incision

Guidewire inserted approximately $2 \mathrm{~cm}$ below the vastus lateralis ridge under $\mathrm{C}$-arm guidance with the help of $135^{\circ}$ angle guide. Guidewire traverse through CCD angle inferiorly in AP view and central in lateral view. This allowed correct placement of anti-rotation screw. Guidewire placed $5 \mathrm{~mm}$ beneath the subchondral bone.

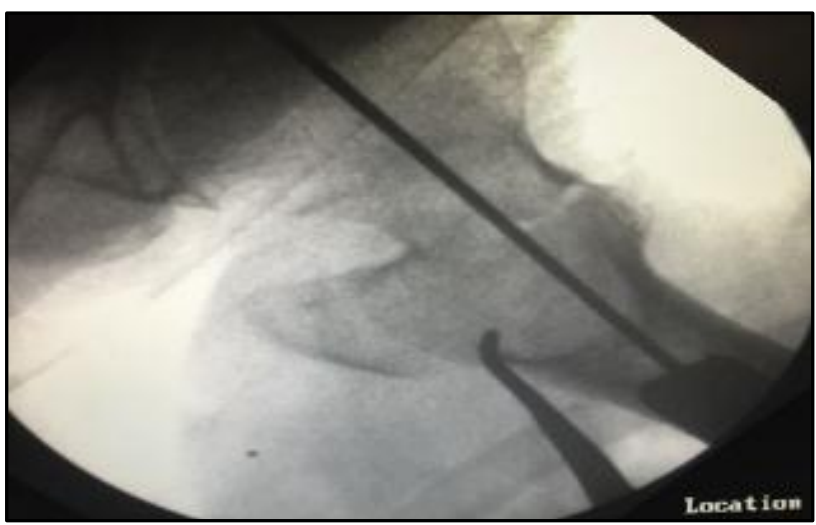

Fig. 5: Guidewire Passed in Central Position in Lateral View

Afterwards guidewire length measured and utilizing a triple reamer reaming done. Adequate size lag screw inserted

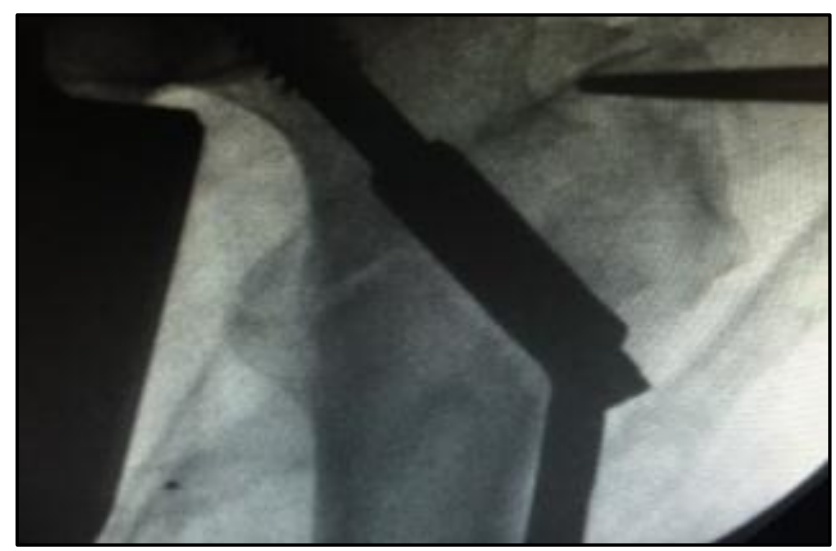

Fig. 6: Lag Screw and Barrel Plate Inserted

A 5-hole barrel plate fixed to lag screw and fixed to shaft of femur using cortical screws in $2^{\text {nd }}$ and $5^{\text {th }}$ hole of plate.

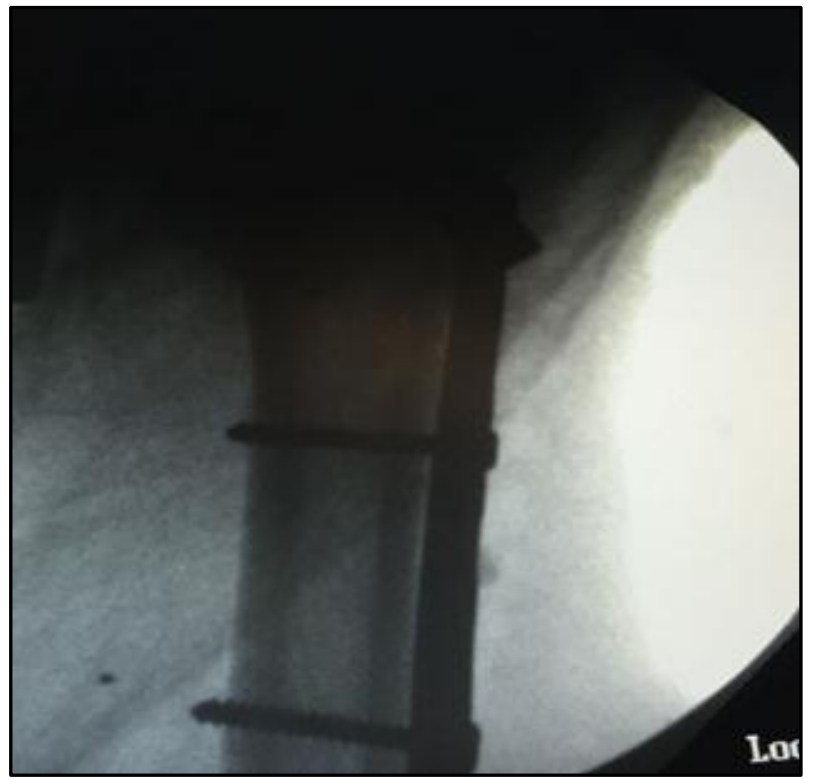

Fig. 7: Barrel Plate Fixed with Cortical Screws in 2nd and 5th Hole

After pre-contouring trochanteric stabilization, plate placed over the plate and fixed using remaining holes in the plate by utilizing cortical screws. Afterwards anti-rotation screw inserted superior to lag screw.

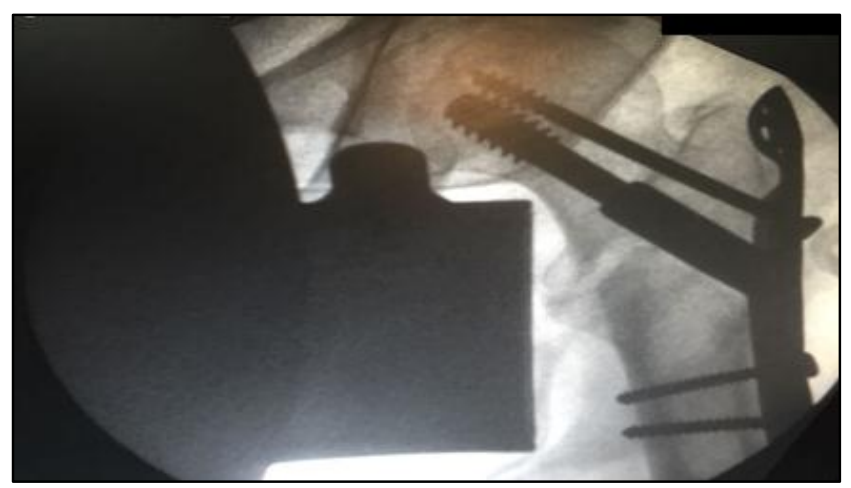

Fig. 8: Anti-Rotation Screw Inserted

If deemed necessary greater trochanter fixed by using 4 $\mathrm{mm}$ cancellous screws or SS wire.

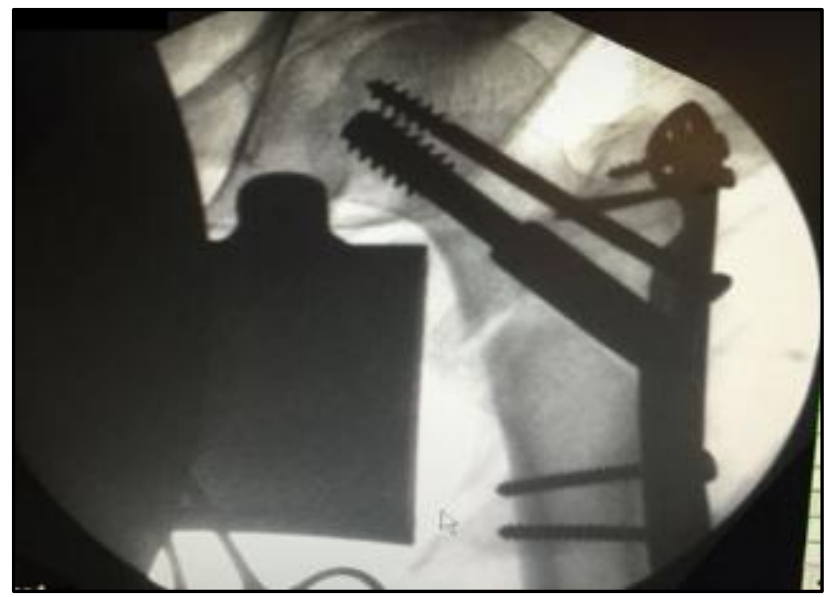

Fig. 9: Cancellous Screws Inserted in Greater Trochanter through TSP 


\section{Post-Operative Protocol}

IV antibiotics and analgesic were given for first two days. From $3^{\text {rd }}$ day onwards oral antibiotics and analgesic were given for another 1 week. Drain removed on $2^{\text {nd }}$ post-operative day. Dressing changed on $2^{\text {nd }}, 6^{\text {th }}$ and $8^{\text {th }}$ post-operative day. Sutures removed on $12^{\text {th }}$ post-operative day. Non-weight bearing mobilization started under guidance of physiotherapist from $3^{\text {rd }}$ postop day. Chest physiotherapy started from $2^{\text {nd }}$ post-operative day. Non-weight bearing mobilization started under guidance of physiotherapist from 3rd postop day. Weight bearing started as soon as possible on the basis of patient's pain tolerance, bone quality, fracture reduction and biomechanical stability of the construct. Patients were followed up once in a month for at least 6 months with appropriate radiographs for assessing union and complications like telescoping and varus collapse.

\section{OBSERVATION}

The study was conducted in Government Kilpauk Medical College and Hospital, Chennai, from October 2013 to November 2015.

25 consecutive patients suffering from unstable intertrochanteric fracture with lateral wall comminution were treated with Trochanteric Stabilization Plate.

In our study, we used AO/OTA classification system for patient selection. We included A031A2 fractures in our study. Three patients migrated to other states, one patient was lost to follow-up and another patient refused follow-up. Thus, twenty patients were followed for mean of 19 months (Range 6 to 28 months).

The distribution of fractures according to type is as follows:

\begin{tabular}{|c|c|}
\hline Type of Fracture & Number of Patients \\
\hline $31 \mathrm{~A} 2.1$ & 3 \\
\hline $31 \mathrm{~A} 2.2$ & 12 \\
\hline $31 \mathrm{~A} 2.3$ & 5 \\
\hline \multicolumn{2}{|c|}{ Type of Fractures } \\
\hline
\end{tabular}

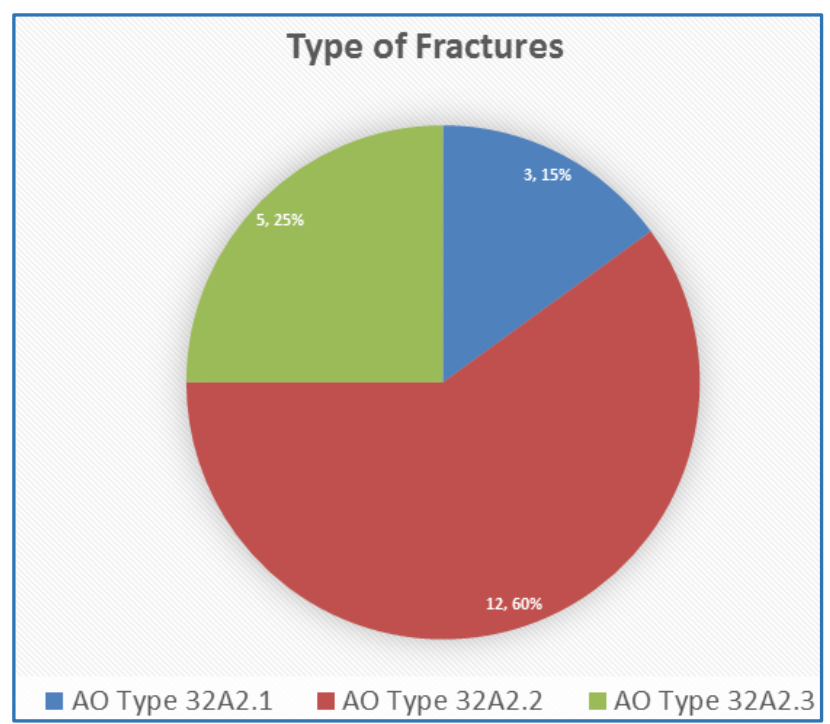

Fig. 101: Type of Fracture

\section{Gender Distribution}

13 patients were male and 7 were female.

Male - 13

Female -7

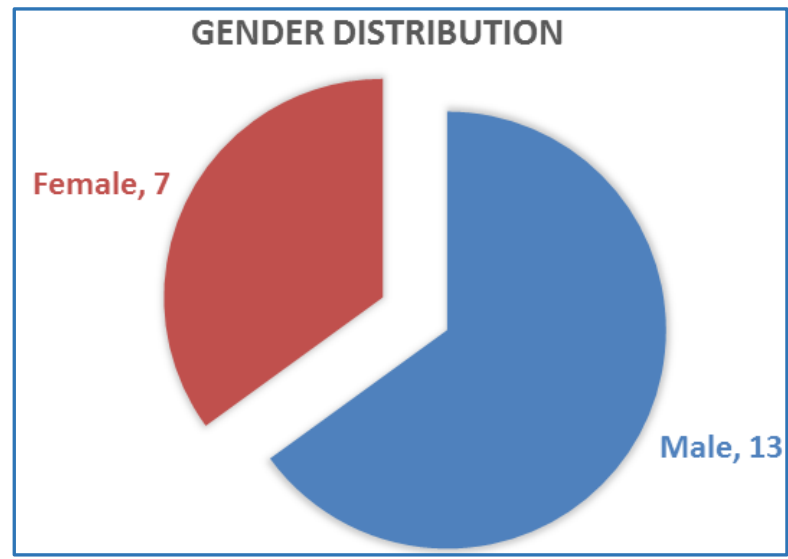

Fig. 11: Gender Distribution

\section{Side of Fracture}

12 patients had left side intertrochanteric fracture and 8 had right side intertrochanteric fracture.

Left - 12

Right - 8

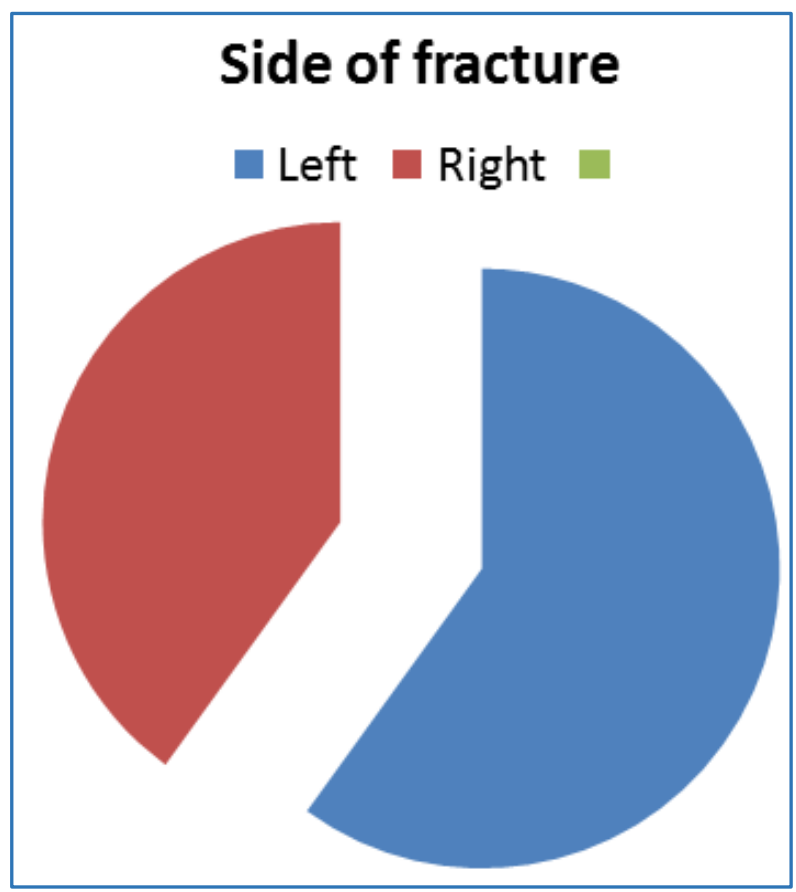

Fig. 12: Side of Fracture

AGE WISE DISTRIBUTION

Age Wise Distribution of Patients is as follows:

\begin{tabular}{|c|c|}
\hline Age Group & No. of Patients \\
\hline $50-60$ & 3 \\
\hline $60-65$ & 7 \\
\hline $66-70$ & 5 \\
\hline $70-75$ & 5 \\
\hline \multicolumn{2}{|c|}{ Age Wise Distribution } \\
\hline
\end{tabular}




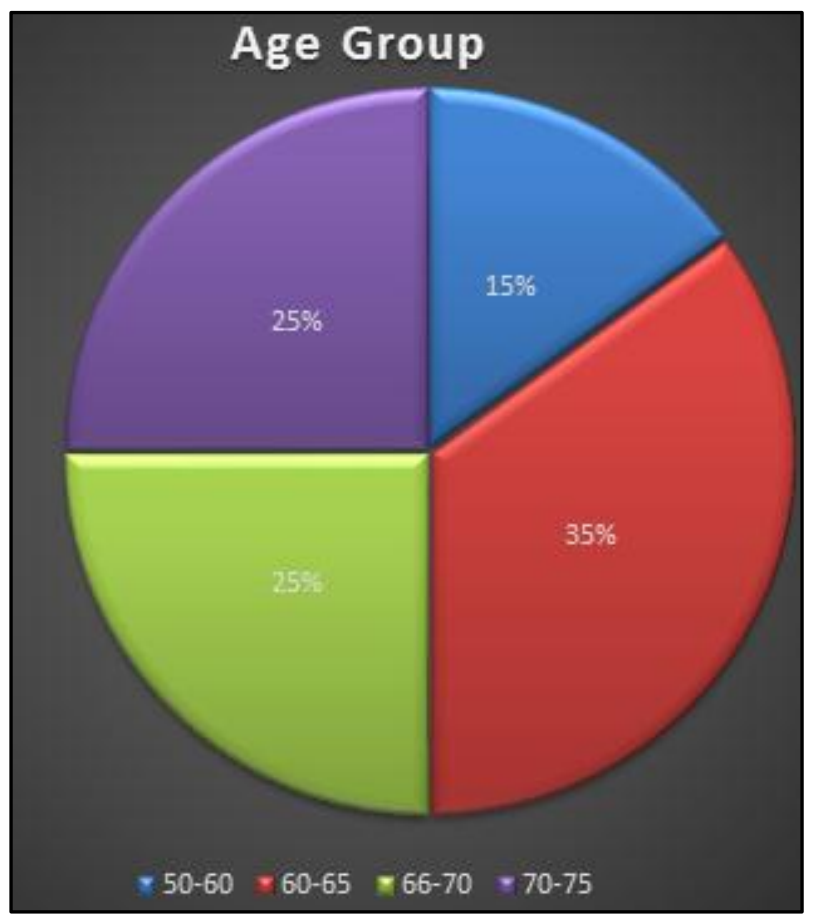

Fig. 13 Age Wise Distribution

\section{Comorbidities}

In our study 8 patients suffered from Type 2 Diabetes Mellitus, 12 patients suffered from systolic hypertension, 3 patients suffered from coronary artery disease, 1 patient suffered from Chronic Kidney Disease and 1 patient had completed treatment for Primary Pulmonary Tuberculosis.

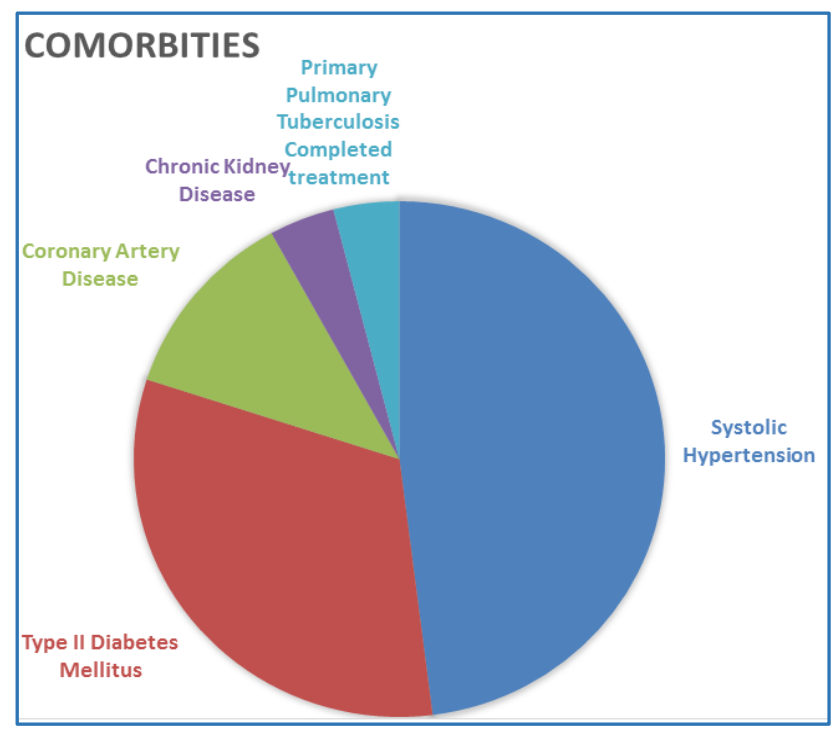

Operative details of Intertrochanteric Fractures treated by TSP

\begin{tabular}{|c|c|}
\hline $\begin{array}{c}\text { Mean time of operation after fracture in } \\
\text { days }\end{array}$ & 7.6 days \\
\hline Mean duration of operation & 82 minutes \\
\hline Mean blood loss in $\mathrm{mL}$ & $166.25 \mathrm{~mL}$ \\
\hline Mean size of lag screw & $85 \mathrm{~mm}$ \\
\hline Mean size of anti-rotation screw & $75 \mathrm{~mm}$ \\
\hline \multicolumn{2}{|c|}{ Operative details } \\
\hline
\end{tabular}

In Postoperative Period, mean duration of hospital stay was 6.9 days. Patient were allowed full weight bearing after an average duration of 13.2 weeks. Two patient had persistent pain in hip region and two patients had persistent thigh pain, hence weight bearing was delayed till radiological union occurred and symptoms subsided.

\begin{tabular}{|c|c|}
\hline Mean duration of hospital stay & 6.9 days \\
\hline Average duration for full weight bearing & 13.2 weeks \\
\hline \multicolumn{2}{|c|}{ Operative Details } \\
\hline
\end{tabular}

\section{RESULTS}

The postoperative radiological outcome was assessed by taking serial X-rays of affected hip in antero-posterior and lateral view. All patients achieved radiological and clinical union; 6 patients underwent radiological union by 16 weeks, 4 patients underwent by 18 weeks, 6 patients underwent union by 20 weeks and 4 patients underwent union by 22 weeks.

Two patients had varus malunion, Average limb length discrepancy was $1.4 \mathrm{~cm}$ with 7 patients having $<1 \mathrm{~cm}$ shortening, 11 had shortening of 1.5 to $2 \mathrm{~cm}$ and 2 had shortening of more than $2 \mathrm{~cm}$ (1 patient had shortening of 2.5 $\mathrm{cm}$ and another had shortening of $2.9 \mathrm{~cm}$ ).

Average time for radiological union was 23.5 weeks.

\section{Functional Outcome}

The postoperative functional outcome was assessed by Harris Hip Score at 20 weeks.

Components of Harris hip score are pain, limp, support, distance walked, stairs climbing, put on shoes and socks, sitting, public transportation, flexion contracture, leg-length discrepancy, absence of deformity and range of motion.

Fig. 14: Comorbidities 


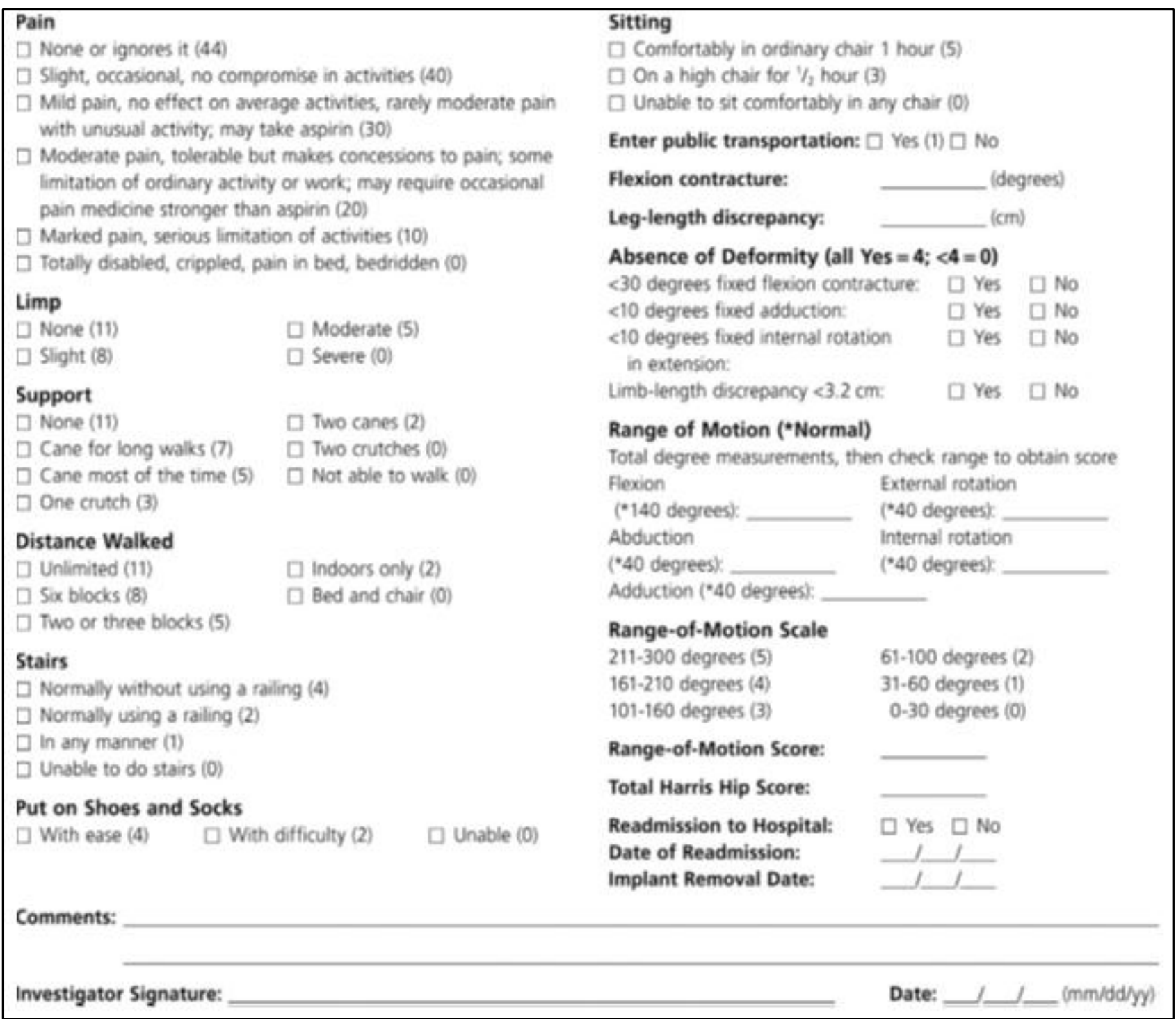

Fig. 15: Harris Hip Score

Average Harris hip score was 83.2. We had 3 excellent results, 14 good results and 3 fair results.

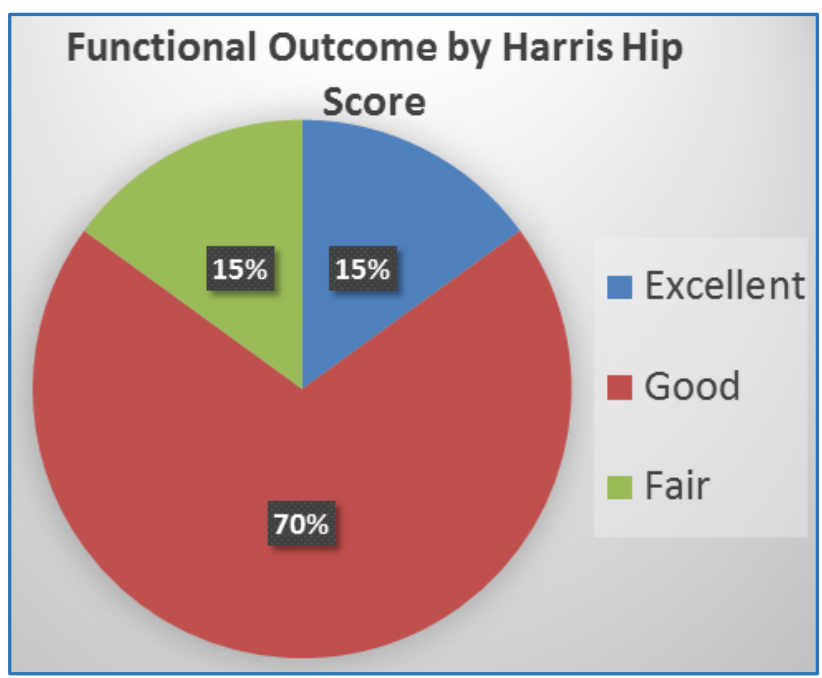

Fig. 16: Functional Outcome by Harris Hip Score

\section{Complications}

The following complications were encountered in patients.

\section{Wound Complications}

One patient had a superficial wound infection. The patient was a female patient suffering from Type II Diabetes Mellitus. The infection subsided with prolonged antibiotics and one sitting of wound wash.

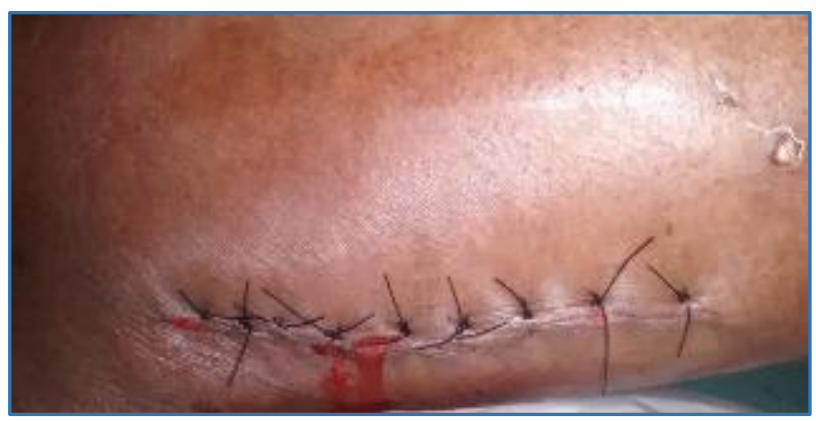

Fig. 17 Wound Infection 
Two male patients had fever on $4^{\text {th }}$ postoperative day. One patient was diagnosed with urinary tract infection and another had lower respiratory tract infection, which settled with a course of antibiotics.

\section{Implant Related Complications}

One patient suffered greater trochanter cancellous screw loosening at 13 weeks. The patient was followed up for another 8 weeks till radiological union occurred and then under spinal anaesthesia the screw was removed.

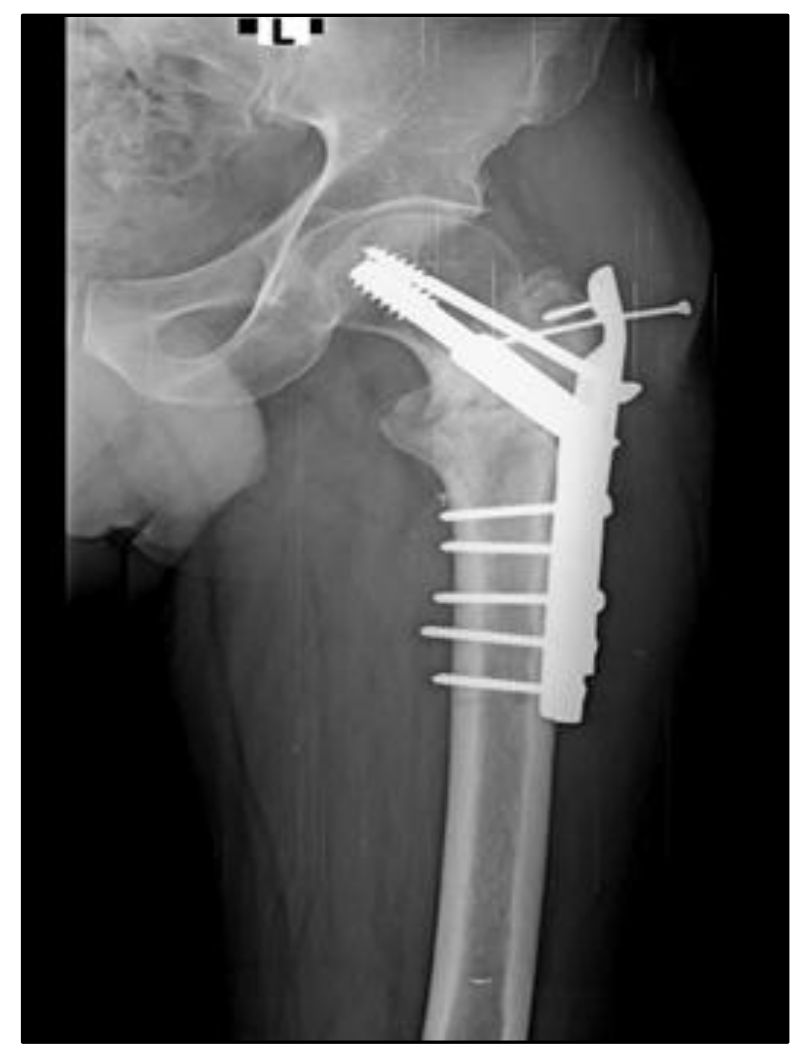

Fig. 18: Screw Back Out

\section{Shortening}

Two patients had shortening of $>2 \mathrm{~cm}$ due to varus collapse, out of which one patient had shortening of $2.5 \mathrm{~cm}$ and another patient had shortening of $2.7 \mathrm{~cm}$.

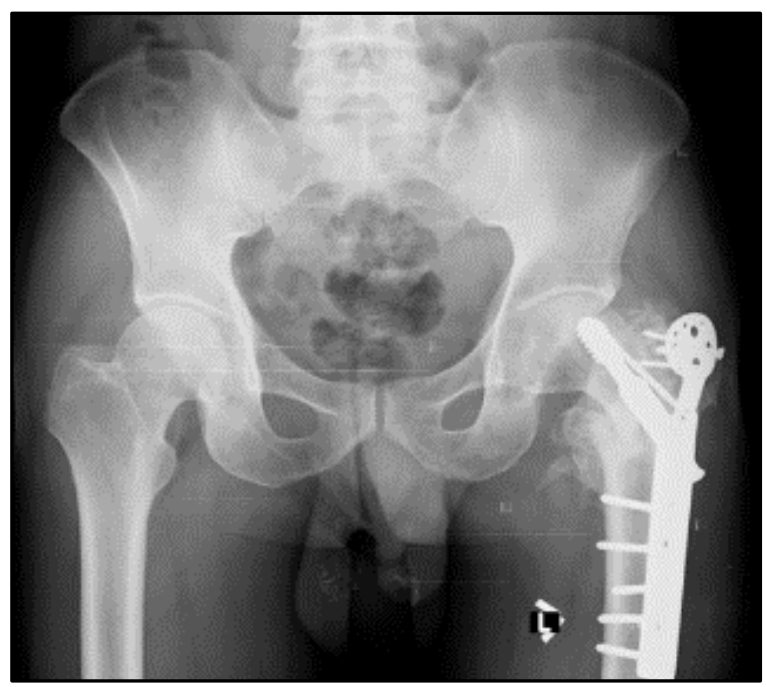

Fig. 19: Varus Collapse
One patient had persistent hip pain and another had persistent thigh pain. Weight bearing was deferred in these patients and pain was relieved after radiological union.

\section{Complications}

\begin{tabular}{|c|c|}
\hline Complications & Total No. of Patients \\
\hline Superficial wound infection & 1 \\
\hline $\begin{array}{c}\text { Screw back-out in greater } \\
\text { trochanter }\end{array}$ & 1 \\
\hline Urinary tract infection & 1 \\
\hline Lower respiratory tract infection \\
\hline $\begin{array}{c}\text { Varus collapse with shortening of } \\
>2 \mathrm{~cm}\end{array}$ & 1 \\
\hline Persistent Hip pain & 2 \\
\hline Persistent Thigh pain & 1 \\
\hline \multicolumn{2}{|c|}{ Complications } \\
\hline
\end{tabular}

\section{RESULTS}

The mean follow-up period was 19 months (range 6-28 months). Lateralization of the greater trochanter was successfully prevented in all fractures. Limited fracture impaction was found in 90 percent $(n=18)$ of the patients with telescoping of 9.5 millimetres (range 0 to 30 millimetres), resulting in mean limb shortening of 5.37 millimetres (range 0 to 14.9 millimetres). Two patients suffered limb shortening exceeding 15 millimetres (range 25 to 27 millimetres). Functional results were excellent or good in 85 percent of patients and fair in 15 percent according to the Harris Hip score. All fractures had healed six months after the operation. Two complications required a secondary procedure: one because of superficial infection and one patient had loosening of screws in greater trochanter.

\section{Year Male}

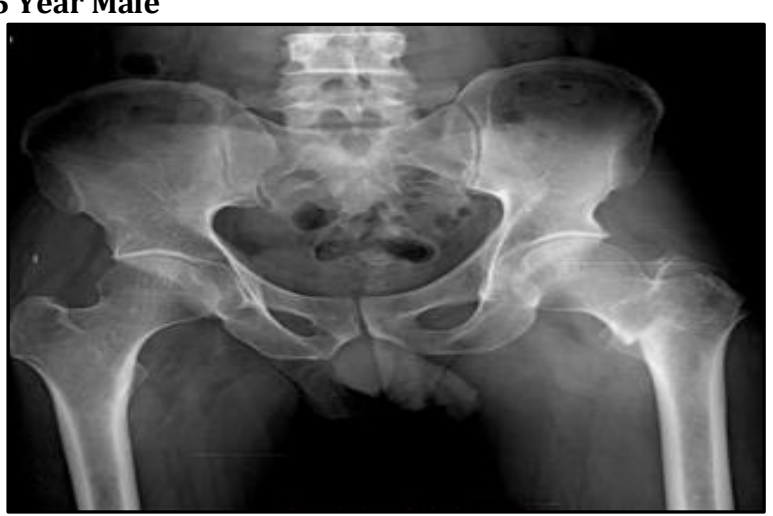

Fig. 20: Preoperative AP View

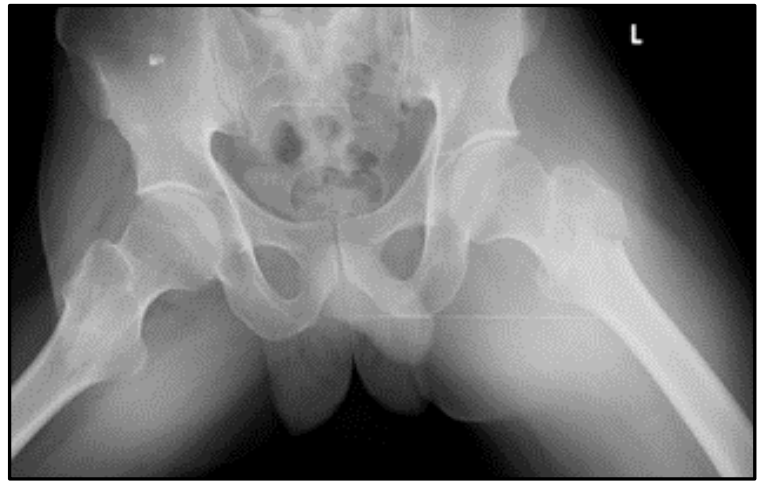

Fig. 21: Preoperative Lateral View 


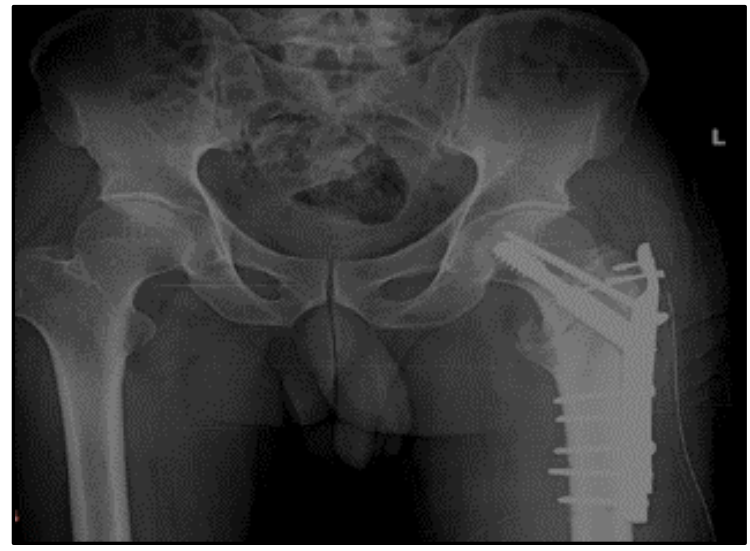

Fig. 22: Immediate Postoperative X-Ray

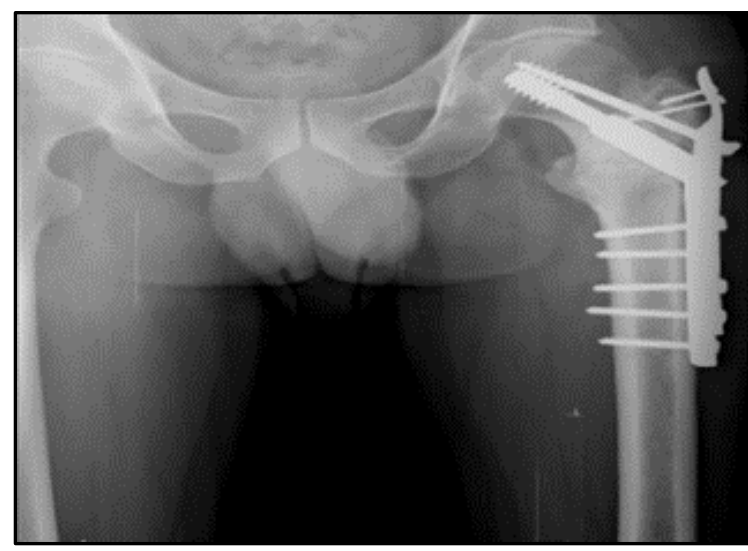

Fig. 23: 18-Month Follow-Up

\section{Case 2}
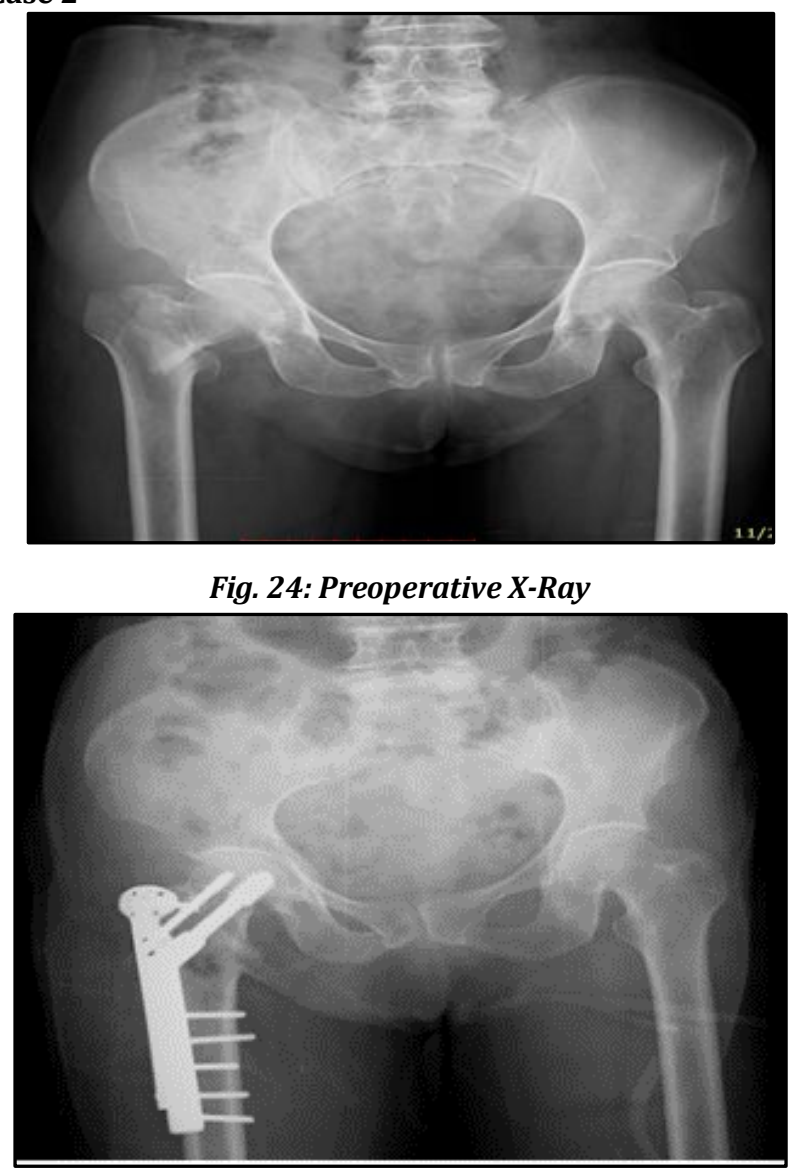

Fig. 25 Immediate Postoperative X-Ray

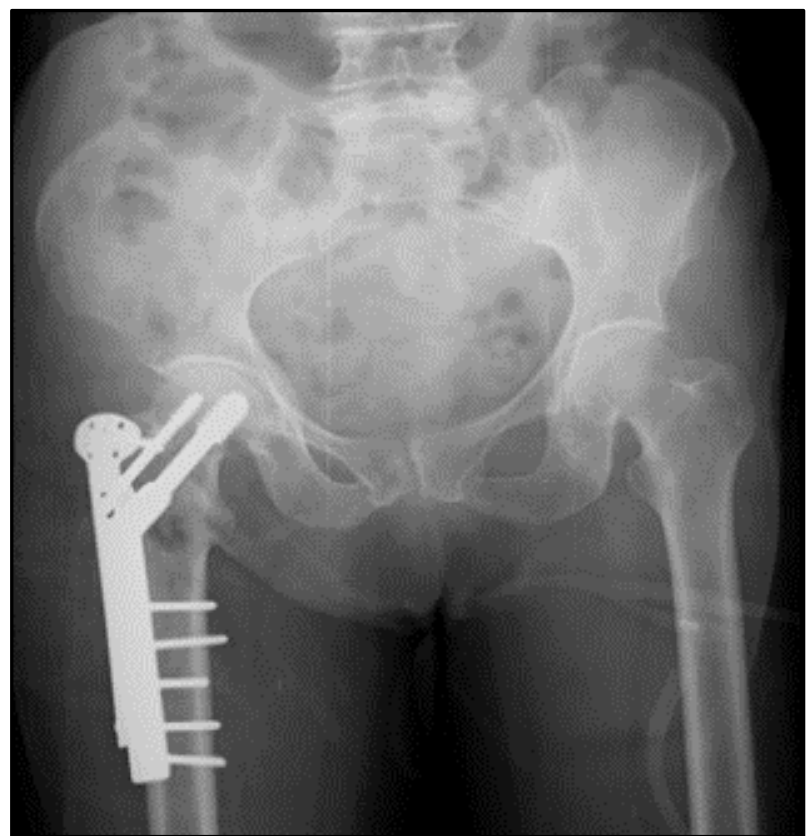

Fig. 26: One and A Half Year Follow-Up X-Ray

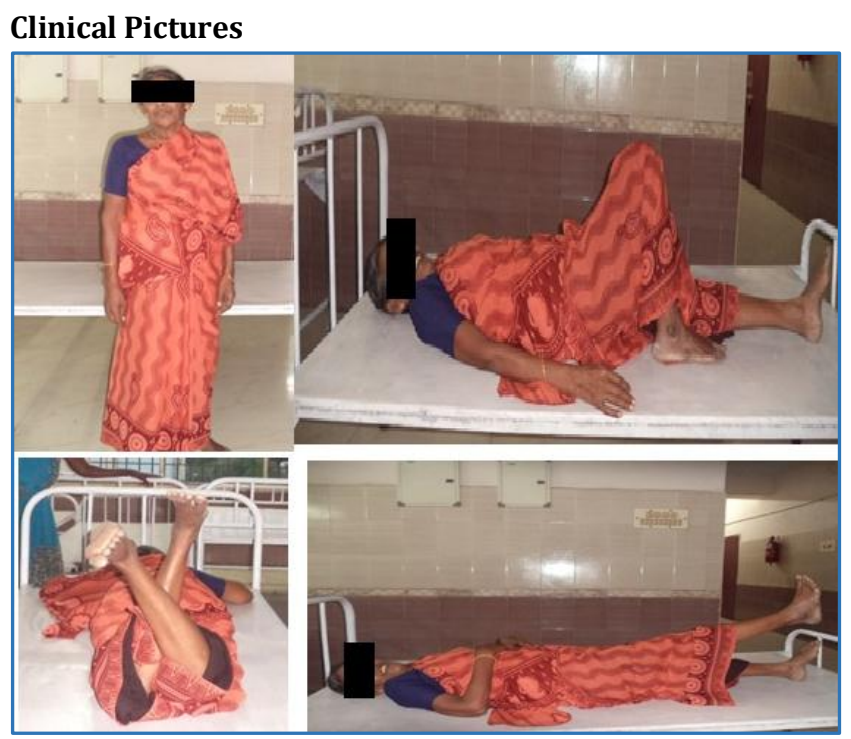

Fig. 32: Clinical Pictures

\section{DISCUSSION}

Intertrochanteric femur fractures contribute half of total hip fractures in the elderly age group of $>60$ years with increase in the life expectancy, the incidence of intertrochanteric hip fractures is increasing.

Simple fall from standing height is the most common mode of injury in this patient. Diminished vision, reduced reflexes, poor muscle tone and balance contribute to the increased incidence.

Various modalities of treatments are available like sliding hip screw, cephalomedullary nails, dynamic condylar screw, hemiarthroplasty and trochanteric stabilization plate. The goal of treatment being early mobilization of patients to prevent fracture disease complication.

Ahrengart et al stated that "less comminuted fractures, the compression hip screw method is the preferred method."(6) Sliding hip screw is still the most widely used implant for these cases. But in case of unstable intertrochanteric fracture with 
lateral wall comminution, it has the disadvantage of excessive varus collapse and screw cut-out. The reason being lack of lateral wall support and single point fixation.

Babst et al, study reported significant reduction in excessive collapse and subsequently reduced limb length discrepancy by using a TSP in combination with the DHS.(7)

International Orthopaedics (SICOT) (2010) 34:125-129 states that improved bony contact between proximal and distal fragments by stabilization of the comminuted lateral wall using TSP is likely to improve the chances of union and maintenance of adequate lever arm. An additional antirotation screw effectively prevents the rotation of the proximal fragment.

R. K. Gupta et al study states that "In unstable trochanteric fractures owing to posterior, medial and lateral comminution, the collapse at the fracture site that occurs with sliding hip screw fixation may be more than usual." In such a situation abductor muscle weakness and its consequent fatigability is likely to be greater. Hence, TSP seems to act as a buttress plate against the medialization of the distal fracture fragment often seen in unstable fractures stabilized with the sliding screw plate systems alone.

Madsen JE et al have stated that "Use of a TSP reduced the secondary lag screw sliding as compared with the conventional CHS without affecting fracture healing."(8)

Hsu C E et al in their series concluded that "the Use of TSP in A2 fractures with critical thin lateral wall thickness $<2.24$ $\mathrm{cm}$ can significantly decrease the lag screw sliding distances, PLWF rate and reoperation rate." $(9)$

\section{In these cases Trochanteric Stabilization Plate provides following benefits: \\ 1. Lateral buttress effect. \\ 2. Anti-rotation screw. \\ 3. Similar technique like sliding hip screw. \\ 4. Small learning curve.}

In our study conducted in Government Kilpauk Medical College and Hospital, Chennai, 20 patients of unstable intertrochanteric fractures with lateral wall comminution were treated with trochanteric stabilization plate and followed up. The fractures were classified according to AO/OTA classification and fractures of AO Type 31A2.1 to 31A2.3 were included in our study.

All cases were followed up for a minimum of 6 months and were assessed for clinical, radiological and functional outcome. The results were analysed. The observations of our study are as follows:

1. Age: Most of the patients in our study were in the age group of 60-70 years.

2. Gender: There was a male preponderance with 13 males and 7 females.

3. Mode of Injury: Fall from standing height was the most common mode of injury.

4. Type of Fracture: In our study we encountered 3 patients of AO Type 31A2.1, 14 patients of AO Type 31A2.2 and 3 patients of AO Type 31A2.3.

5. Side of Fracture: 12 patients suffered fracture on left side and 8 patients suffered fracture on right side.

6. Comorbidities: 2 patients had systolic hypertension and type 2 diabetes mellitus; 2 patients had coronary artery disease and type 2 diabetes mellitus; 1 patient suffered from chronic kidney disease and systolic hypertension; 10 patients suffered from isolated systolic hypertension; 6 patients suffered from isolated diabetes mellitus; 1 patient was a known case of old healed pulmonary tuberculosis and completed Category 1 anti-TB treatment.

7. All the patients had good preoperative mobility and were ambulating independently unassisted.

8. Majority of patients were operated within 7 days, the average being 7.6 days.

9. Mean operating time was 82 minutes.

10. Mean blood loss was $166.25 \mathrm{~mL}$

11. Mean length of incision was $11.75 \mathrm{~cm}$. On an average, it was $2.75 \mathrm{~cm}$ larger than routine DHS incision. Longer incision was required for applying trochanteric stabilization plate.

12. Mean lag screw size was $85 \mathrm{~mm}$, mean anti-rotation screw ( $6.5 \mathrm{~mm}$ cancellous screw) size was $75 \mathrm{~mm}$.

13. Average hospital stay was 6.9 days.

14. Partial weight bearing was allowed immediately on $3^{\text {rd }}$ postoperative day on the basis of construct stability and bone quality.

15. All fractures united on an average of 16.75 weeks.

16. All patients were allowed to full weight bearing on an average by 13.2 weeks on the basis of clinical and radiological union.

17. After analysing functional outcome of all patients by Harris hip score, the average score was found to be 83.2. We had 3 excellent results, 14 good results and 3 fair results.

18. Complications: One patient, known case of Type 2 diabetes mellitus suffered from superficial wound infection. One patient suffered from urinary tract infection and one patient suffered from lower respiratory tract infection. Two patients suffered varus collapse with limb shortening $>2 \mathrm{~cm}$. One patient suffered greater trochanter cancellous screw back-out.

In our study, modular extension of DHS with TSP prevented varus collapse and limb length discrepancy in $90 \%$ cases.

\section{CONCLUSION}

Trochanteric stabilization plate with sliding hip screw is a biomechanically stable construct allowing reconstruction of lateral wall to maintain adequate lever arm and abductor strength (Power arm) in unstable intertrochanteric fractures with lateral wall comminution.

Additional anti-rotation screw provides enhanced rotational stability to the proximal fragment. Lateral wall buttress effect reduces the chance of varus collapse and screw cut-out. The operative technique being similar to sliding hip screw, it has a small learning curve.

Overall, in patients with unstable intertrochanteric fractures with lateral wall comminution, trochanteric stabilization plate can give a superior functional and radiological outcome.

\section{REFERENCES}

1. Davis TRC, Sher JL, Horsman A, et al. Intertrochanteric femoral fractures: mechanical failure after internal fixation. J Bone Joint Surg 1990;72(1):26-31. 
2. Ecker ML, Joyce JJ, Kohl JE. The treatment of trochanteric hip fractures using a compression screw. J Bone Joint Surg 1975;57(1):23-7.

3. Gotfried Y. The lateral trochanteric wall: a key element in the reconstruction of unstable per trochanteric hip fractures. Clin Orthop Relat Res 2004;425:82-6.

4. Frohlich P, Benko T. DHS (dynamic hip screw) osteosynthesis in the management of femoral fractures in the hip region and the place of this method in the treatment of such injuries. Magy Traumatol Ortop Kezseb Plasztikai Sch 1993;36(1):59-64.

5. Bannister GC, Gibson AG, Ackroyd CE, et al. The closed reduction trochanteric fractures. J Bone Joint Surg Br 1990;72(2):317.

6. Ahrengart L, Törnkvist H, Fornander $\mathrm{P}$, et al. A randomized study of the compression hip screw and Gamma nail in 426 fractures. Clin Orthop Relat Res 2002;401:209-22.
7. Babst R, Renner N, Biedermann M, et al. Clinical results using the trochanter stabilizing plate (TSP): The modular extension of the dynamic hip screw (DHS) for internal fixation of selected unstable intertrochanteric fractures. J Orthop Trauma 1998;12(6):392-9.

8. Madsen JE, Naess L, Aune AK, et al. Dynamic hip screw with trochanteric stabilizing plate in the treatment of unstable proximal femoral fractures: a comparative study with the Gamma nail and compression hip screw. J Orthop Trauma 1998;12(4):241-8.

9. Hsu CE, Chiu YC, Tsai SH, et al. Trochanter stabilizing plate improves treatment outcomes in AO/OTA 31-A2 intertrochanteric fractures with critical thin femoral lateral walls. Injury Int J Care Injured 2015;46(6): 1047-53. 